\title{
Mediating Effect of Internet Addiction on the Association between Resilience and Depression among Korean University Students: A Structural Equation Modeling Approach
}

\author{
Kwok Kei Mak', Jaeseung Jeong ${ }^{2}$, Hye-Kyung Lee ${ }^{3}$, and Kounseok Lee ${ }^{4}$ \\ ${ }^{1}$ Department of Statistics, Keimyung University, Daegu, Republic of Korea \\ ${ }^{2}$ Department of Bio and Brain Engineering, Korea Advanced Institute of Science and Technology (KAIST), Daejeon, Republic of Korea \\ ${ }^{3}$ Department of Nursing, College of Nursing and Health, Kongju National University, Gongju, Republic of Korea \\ ${ }^{4}$ Department of Psychiatry, Gangnam Eulji Hospital, Seoul, Republic of Korea
}

\begin{abstract}
Objective This study examined the mediating role of internet addiction in the association between psychological resilience and depressive symptoms.

Methods 837 Korean university students completed a survey with items of demographic information, Connor-Davidson Resilience Scale (CD-RISC), Internet Addiction Test (IAT), and Patient Health Questionnaire (PHQ-9) in 2015. The complex associations among psychological resilience, internet addiction, and depressive symptoms were delineated using structural equation models.

Results In the most parsimonious model, the total effect and indirect effect of resilience on depressive symptoms via internet addiction, were statistically significant. The goodness of fit of the measurement model was satisfactory with fit indices, normed fit index (NFI) of 0.990 , non-normed fit index (NNFI) of 0.997 , comparative fit index (CFI) of 0.998 , root mean square error (RMSEA) of 0.018 (90\% CI=0.001-0.034); and Akaike Information Criterion (AIC) of -21.049.

Conclusion The association between psychological resilience and depressive symptoms was mediated by internet addiction in Korean university students. Enhancement of resilience programs could help prevent internet addiction and reduce the related depression risks.
\end{abstract}

Psychiatry Investig 2018;15(10):962-969

Key Words Mediation, Internet addiction, Resilience, Depression, University students.

\section{INTRODUCTION}

Depressive symptoms are important to the diagnosis of sub-threshold types of depression in psychiatric practices. ${ }^{1}$ The UK National Institute for Health and Care Excellence (NICE) guidance of diagnostic and management of depression advises healthcare professionals to maintain a high awareness of depressive symptoms among young people. ${ }^{2}$ Although depression is a major internalizing disorder in adolescents, ${ }^{3}$ not everyone could acquire the respective coping

Received: February 22, 2018 Revised: July 7, 2018

Accepted: August 7, 2018

$\triangle$ Correspondence: Kounseok Lee, MD, PhD

Department of Psychiatry, Gangnam Eulji Hospital, 202 Dosan-daero, Gangnam-gu, Seoul 06047, Republic of Korea

Tel: +82-2-3438-1155, Fax: +82-2-3438-1001, E-mail: countin@gmail.com

(a) This is an Open Access article distributed under the terms of the Creative Commons Attribution Non-Commercial License (http://creativecommons.org/licenses/bync/4.0) which permits unrestricted non-commercial use, distribution, and reproduction in any medium, provided the original work is properly cited. strategies. ${ }^{4}$ Furthermore, tracking of depression from adolescence to adulthood is not uncommon. ${ }^{5}$

Transition from adolescence to adulthood provides an opportunity for individuals to further develop their psychological resilience. ${ }^{6}$ Psychological resilience is a concept derived from the vulnerability principle, ${ }^{7}$ with emerging neurological evidence of its self-regulatory function. ${ }^{8}$ A 10 -year cohort study has reported that CACNA1C SNP rs1006737 was a predisposition of resilience to depressive symptoms. ${ }^{9}$ Magnetic resonance imagining (MRI) studies have shown high grey matter volumes at the right middle and superior frontal gyri ${ }^{10}$ and high fractional anisotropy (FA) in the anterior corpus callosum (CC) among resilient adolescents when compared with others. ${ }^{11}$ Hippocampal volume also served as a valid neural marker for assessing both psychological resilience and depression. ${ }^{12}$

Epidemiological studies have also shown the relationships between health-related behaviors and psychological resilience to negative affects in adolescents. ${ }^{13}$ School-based resil- 
ience trials for reducing substance use were found to be effective in adolescents. ${ }^{14,15}$ In young adults, related resilience findings are mostly on substance uses, such as smoking ${ }^{16}$ and drug use. ${ }^{17}$ Individuals with addictive internet behaviors shared certain personality features with alcohol dependents, ${ }^{18}$ including impulsivity. ${ }^{19} \mathrm{~A}$ systematic review has stipulated depression and anxiety as the psychological symptoms of addictive internet behaviors. ${ }^{20}$ While there are findings showing the mediation model among resilience, internet addiction, and depression in children, no corresponding results in youth is available for clinical references. ${ }^{21}$

This study examined the possible associations between resilience, depressive symptoms, and internet addiction with the following hypotheses: Hypothesis 1 (H1) is that resilience is negatively associated with the likelihood of internet addiction; Hypothesis 2 (H2) is that internet addiction is positively associated with depressive symptoms; Hypothesis 3 (H3) is that resilience is negatively associated with depressive symptoms.

\section{Hypothesis 1}

We hypothesize that better resilience will be associated with a lower likelihood of internet addiction. Previous studies have shown that psychological resilience was negatively associated with the risk of Internet addiction in children ${ }^{21}$ and adolescents $(\beta=-0.030){ }^{22}$ Similar associations were found in university students. ${ }^{23,24}$ In Korean university students, the correlation coefficient between CD-RISC scores and IAT scores was $-0.12^{25}$ and smartphone users (mean $=59.06$ ) had a significantly lower CD-RISC-determined resilience in at-risk than normal users $($ mean $=66.54) .{ }^{26}$

\section{Hypothesis 2}

We hypothesize that internet addiction will be associated with depressive symptoms. Together with anxiety, depression is one of the major psychological factors of internet addiction in young people. ${ }^{27}$ The associations between depressive symptoms and Internet addiction are well-established from studies with vary measurement scales. ${ }^{28-31}$ Longitudinal study results also showed the causation between addicted online relationships and depressive symptoms in adolescents. ${ }^{32}$ Depressive symptoms were also linked to poor psychosocial wellbeing via internet addiction in cross-population adolescent studies. ${ }^{33}$ In adults, Internet addicted group was more likely to have depressive symptoms than others. ${ }^{34}$ In university students, internet addiction was related to a higher risk of Beck Depression Inventory (BDI)-determined depression in Turkey. ${ }^{27}$

\section{Hypothesis 3}

We hypothesize that better psychological resilience will be associated with less symptoms of depressive symptoms. According to the depression model proposed by Beck and Bredemeier, ${ }^{35}$ positive predisposing, precipitating, and resilience factors all could reduce depressive symptoms. A youth cohort in Australia found that CD-RISC determined resilience led to Goldberg Depression and Anxiety Inventory-determined depressive symptoms. ${ }^{36}$ In Korean adults with parental alcoholism, CD-RISCdetermined resilience helped prevent the development of Beck Depression Inventory-determined depressive symptoms. ${ }^{37}$

Based the three associations, several adolescent studies have further investigated the role of internet addiction in the associations between psychological resilience and negative affects. Resilience could mitigate the negative effects (measured by the Watson's Positive and Negative Affect Scales) of internet addiction in US adolescents aged 13 to $17 .^{38} \mathrm{~A}$ previous study among Chinese adolescents suggested that life events could mediate the association between internet addiction and depression. ${ }^{39}$ Another Korean high school study suggested that psychological resilience could be associated with internet addiction via stress. ${ }^{40}$

According to the 2016 Epidemiological Survey of Mental Disorders by the Ministry of Health and Welfare, the lifetime prevalence of major depressive disorder in Korean adults was $5.0 \%$. Among university students in Korea, keen academic competitions and career uncertainties are common and depression was a major risk factor of suicides. ${ }^{41}$ However, the behavioral risk factors of suicidal ideation could be different between university men and women in Korea. ${ }^{42}$ This study aimed to delineate the complex relationships of resilience, depressive symptoms, and internet addiction among Korean university students with a structural equation modeling approach.

\section{METHODS}

\section{Administration}

Students from a university in the Chungcheong Province of Korea were invited to complete a questionnaire in Korean language online in 2015. Informed consent was sought and their participations were voluntary and no incentive was provided. A total of 1184 students were invited, with 846 completed questionnaires received and 837 agreed to provide the information for research. Ethics approval was obtained from the Institutional Review Board of Kongju National University (KNU_IRB_2015-38).

\section{Measures}

In addition to demographic information, students responded to the following scale measures, Connor-Davidson Resilience Scale (CD-RISC) (25 items), Internet Addiction Test (IAT) (20 items), and Patient Depression Questionnaire (PHQ-9) (9 items). The 25-item Connor-Davidson Resil- 
ience Scale is a common scale to assess psychological resilience, ${ }^{43}$ although its short-form 10-item Connor-Davidson Resilience Scale is available. ${ }^{44}$ The five factors for CD-RISC are a) Personal Competence, b) Trust and Tolerance, c) Acceptance and Relationship Security, d) Control, and e) Spiritual influence. The responses are 5-point Likert scale ("Not true At all," "Rarely true," "Sometimes true," "Often true," "True nearly all of the time"). The possible total scores for CD-RISC are from 0 to 100, with higher score representing a better resilience level. Internet Addiction Test (IAT) has six responses ("Never or not applicable," "Rarely," "Occasionally," "Sometimes," "Often," "Always"). The possible scores for IAT are 0 to 100 , with higher score representing a higher risk of internet addiction. Besides, IAT has been translated and tested in college students across countries ${ }^{45-47}$ including Korean college students ${ }^{48}$ in which four factor structure was revealed. The PHQ-9 has four responses, including "not at all," several days," "more than half the days," "nearly every day." In addition, PHQ-9 has been tested among US ${ }^{49}$ and Chinese college students. ${ }^{50}$ An one-factor structure of PHQ-9 was found to be reliable (Cronbach's alpha $=0.837$ ), test-retest reliable $(\mathrm{r}=0.650)$, and valid against Depression Inventory (BDI) and Perceived Stress Scale (PSS) ( $\mathrm{r}=0.509$ to 0.807 ) among Korean medical students. ${ }^{51}$ The possible scores range from 0 to 27 , with a higher score indicating more depressive symptoms.

\section{Data analysis}

A total of 837 students were included in the main analysis. Gender differences of and correlations between the scales were tested using t-test and Pearson correlation coefficient, respectively. Possible conceptual models (Models 1 to 4 ) for modeling the relationships between resilience, depression, and internet addiction were constructed for comparisons (Figure 1). Structural equation modeling (SEM) was conducted to compute the model fit indices using the robust maximum likelihood method. Goodness-of-fit was regarded as acceptable if the values of normed fit index (NFI), and nonnormed fit index (NNFI); ${ }^{52}$ and comparative fit index (CFI) $;^{53}$ were above 0.90 ; as well as root mean square error of approximation (RMSEA) ${ }^{54}$ were below $0.08 .^{55}$ The significance of the paths in the model was indicated by the Wald test. Models with smaller normal Akaike's Information Criterion (AIC) values were preferred. All analyses were performed using SPSS 21.0 for Windows (IBM Inc., Armonk, NY, USA) and EQS 6 (Multivariate Software, Encino, CA ,USA).

\section{RESULTS}

\section{Descriptive statistics}

As shown in Table 1, university men had significantly
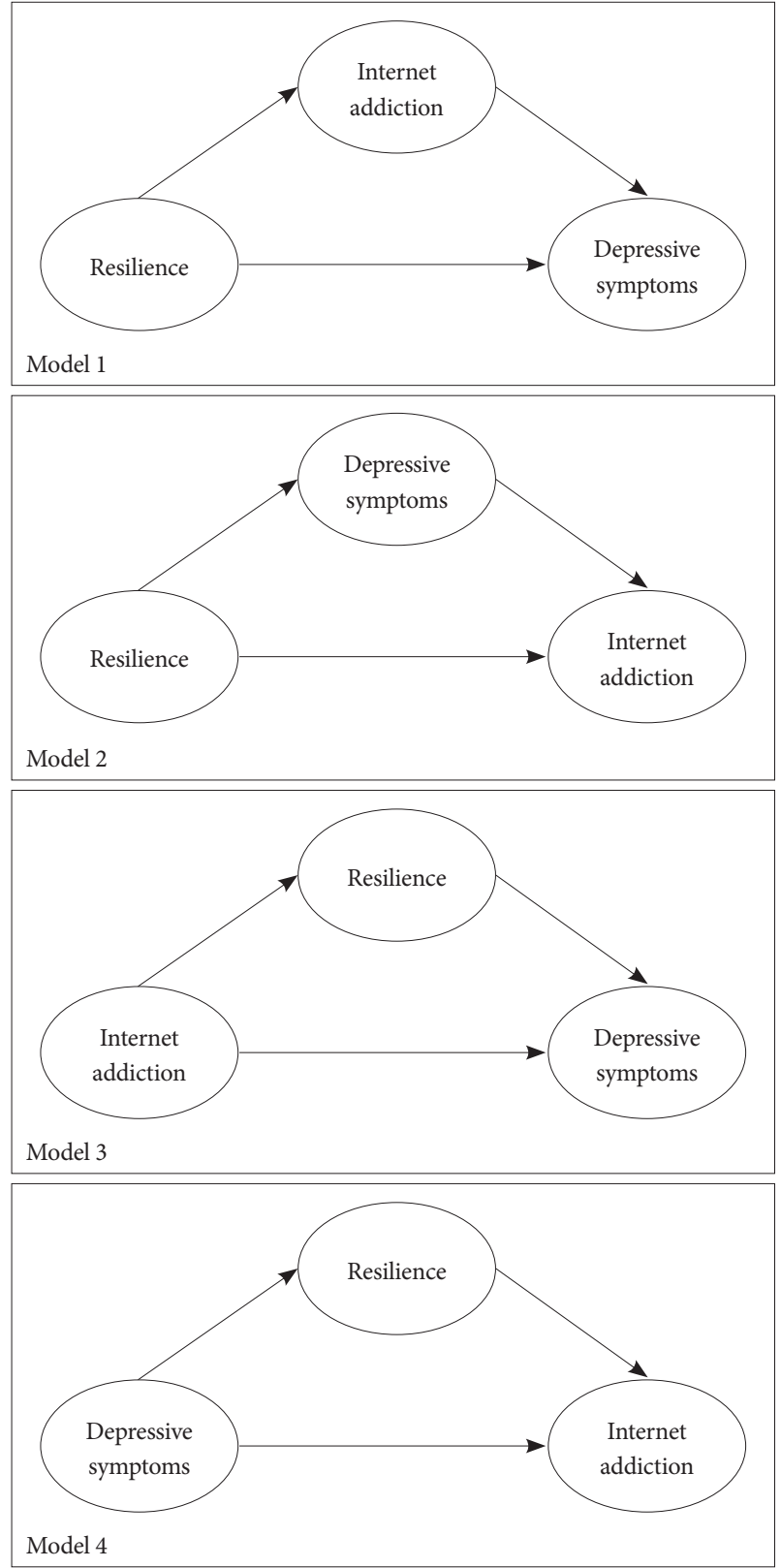

Figure 1. Conceptual models for structural equation modeling.

higher CD-RISC total scores than women (63.88 SD=15.33 vs. $55.60 \mathrm{SD}=15.70)$. However, university women had significantly higher PHQ-9 scores than men $(6.25, \mathrm{SD}=4.68$ vs. $4.96, \mathrm{SD}=5.07)$. There was no significant difference of IAT and its subscale scores between university men and women. Their respective IAT total scores were $22.14(\mathrm{SD}=15.22)$ and 22.41 ( $\mathrm{SD}=16.97$ ). The major scales, CD-RISC, PHQ-9, and IAT showed good internal consistency with corresponding Cronbach's alpha values of $0.940,0.865$, and 0.946 . In Table 2, CD-RISC-Total significantly $(\mathrm{p}<0.01)$ and negatively correlated with PHQ-9-Total $(\mathrm{r}=-0.500)$ and IAT-Total $(\mathrm{r}=-0.320)$. The correlation between PHQ-9-Total and IAT-Total was 
Table 1. Basic characteristics and measure scores

\begin{tabular}{|c|c|c|c|c|}
\hline & $\begin{array}{c}\text { Men }(\mathrm{N}=361) \\
\text { Mean }(\mathrm{SD})\end{array}$ & $\begin{array}{c}\text { Women }(\mathrm{N}=476) \\
\text { Mean }(\mathrm{SD})\end{array}$ & t-value & p-value \\
\hline Age & $22.7(2.37)$ & $21.7(1.82)$ & 7.246 & $<0.001$ \\
\hline CD-RISC-total (Cronbach's $\alpha=0.940$ ) & $63.88(15.33)$ & $55.6(15.70)$ & 7.655 & $<0.001$ \\
\hline CD-RISC personal competency and tenancy (8 items) & $20.57(5.72)$ & $17.30(5.79)$ & 8.133 & $<0.001$ \\
\hline CD-RISC trust and tolerance ( 7 items) & $17.27(4.60)$ & $14.44(4.67)$ & 8.784 & $<0.001$ \\
\hline CD-RISC acceptance of change and relationship security (5 items) & $13.98(3.44)$ & $12.87(3.47)$ & 4.590 & $<0.001$ \\
\hline CD-RISC control (3 items) & $7.40(2.49)$ & $6.71(2.55)$ & 3.946 & $<0.001$ \\
\hline CD-RISC spiritual influences (2 items) & $4.66(1.54)$ & $4.29(1.74)$ & 3.293 & 0.001 \\
\hline PHQ (9-items) (Cronbach's $\alpha=0.865$ ) & $4.96(5.07)$ & $6.25(4.68)$ & -3.749 & $<0.001$ \\
\hline IAT-total (20 items) (Cronbach's $\alpha=0.946)$ & $22.14(15.22)$ & $22.41(16.97)$ & -0.239 & 0.81 \\
\hline IAT-time management (9 items) & $13.35(8.87)$ & $13.04(9.49)$ & -0.925 & 0.355 \\
\hline IAT-dependence (5 items) & $4.17(3.71)$ & $4.27(4.31)$ & -0.350 & 0.727 \\
\hline IAT-withdrawal (3 items) & $1.91(2.19)$ & $1.93(2.52)$ & -0.105 & 0.916 \\
\hline IAT-avoidance of reality ( 3 items) & $2.71(2.39)$ & $2.27(2.49)$ & 2.578 & 0.010 \\
\hline
\end{tabular}

CD-RISC: Connor-Davidson Resilience Scale, PHQ-9: Patient Health Questionnaire, IAT: Internet Addiction Test, SD: standard deviation

Table 2. Pearson correlation coefficients among measure scores

\begin{tabular}{lccc}
\hline & CD-RISC-total & PHQ-9-total & IAT-total \\
\hline Men & & & \\
CD-RISC-total & 1 & & \\
PHQ-9-total & $-0.469^{*}$ & 1 & \\
IAT-total & $-0.400^{*}$ & $0.332^{*}$ & 1 \\
Women & & & \\
CD-RISC-total & 1 & & \\
PHQ-9-total & $-0.503^{*}$ & 1 & \\
IAT-total & $-0.282^{*}$ & $0.237^{*}$ & 1 \\
All & & & \\
CD-RISC-total & 1 & $-0.500^{*}$ & $-0.320^{*}$ \\
CD-RISC-PCT & & $-0.436^{*}$ & $-0.327^{*}$ \\
CD-RISC-TT & & $-0.438^{*}$ & $-0.232^{*}$ \\
CD-RISC-ACRS & & $-0.481^{*}$ & $-0.296^{*}$ \\
CD-RISC-C & & $-0.456^{*}$ & $-0.328^{*}$ \\
CD-RISC-SI & & $-0.279^{*}$ & $-0.111^{*}$ \\
PHQ-9-total & & 1 & \\
IAT-total & $-0.320^{*}$ & $0.275^{*}$ & 1 \\
IAT-TM & $-0.302^{*}$ & $0.253^{*}$ & \\
IAT-D & $-0.314^{*}$ & $0.260^{*}$ & \\
IAT-W & $-0.246^{*}$ & $0.188^{*}$ & \\
IAT-AR & $-0.223^{*}$ & $0.254^{*}$ & \\
\hline
\end{tabular}

${ }^{*} \mathrm{p}<0.01$. CD-RISC: Connor-Davidson Resilience Scale, CD-RISCPCT: CD-RISC Personal Competency and Tenancy, CD-RISCTT: CD-RISC Trust and Tolerance, CD-RISC-ACRS: CD-RISCAcceptance of Change and Relationship Security, CD-RISC-C: CD-RISC Control, CD-RISC-SI: CD-RISC Spiritual Influences, IAT: Internet Addiction Test, IAT-TM: IAT-Time Management, IAT-D: IAT-Dependence, IAT-W: IAT-Withdrawal, IAT-AR: IATAvoidance of Reality, PHQ-9: Patient Health Questionnaire also significant $(\mathrm{p}<0.01)$ and positive $(\mathrm{r}=0.275)$. Significant correlations of same directions between these scale total values were found after stratification by sex. In addition, the subscales of CD-RISC, PHQ-9, and IAT also significantly correlated with each other.

\section{Structural equation modeling}

In Model 1, resilience had a significant and negative total effect on depressive symptoms $(\beta=-0.981, \mathrm{SE}=0.514, \mathrm{p}<0.001)$. When internet addiction was considered as a mediator, resilience had a significant and negative indirect effect on depressive symptoms $(\beta=-0.073, \mathrm{SE}=0.183, \mathrm{p}<0.001)$. The direct effects of resilience on depressive symptoms $(\beta=-0.908)$ and internet addiction ( $\beta=-0.350)$ were significant and negative (Figure 2). In addition, the direct effect of depressive symptoms on internet addiction was significant and positive $(\beta=0.208)$. The values of the fit indices for Model 1 were as follow: NFI of 0.990 , NNFI of 0.997 , CFI of 0.998 , RMSEA of 0.018 (90\%CI=0.001-0.034), and AIC of -21.049 (Table 3 and 4).

In Model 2, resilience had a significant and negative total effect on Internet addiction ( $\beta=-0.350, \mathrm{SE}=0.065, \mathrm{p}<0.001$ ). With depressive symptoms acting as a mediator, resilience had a significant and negative indirect effect on internet addiction $(\beta=-0.337, \mathrm{SE}=0.110, \mathrm{p}<0.001)$. The fit indices for Model 2 were satisfactory with NFI of 0.974 , NNFI of 0.972 , CFI of 0.982 , and RMSEA of $0.052(90 \% \mathrm{CI}=0.040-0.063)$, and AIC of 35.412 (Table 3 and 4). In Model 3, internet addiction had a significant and positive total effect on depressive symptoms $(\beta=0.506, \mathrm{SE}=0.202, \mathrm{p}<0.001)$. Internet addiction had a significant and positive indirect effect on depressive symptoms, via resilience $(\beta=0.306, \mathrm{SE}=0.113$, 


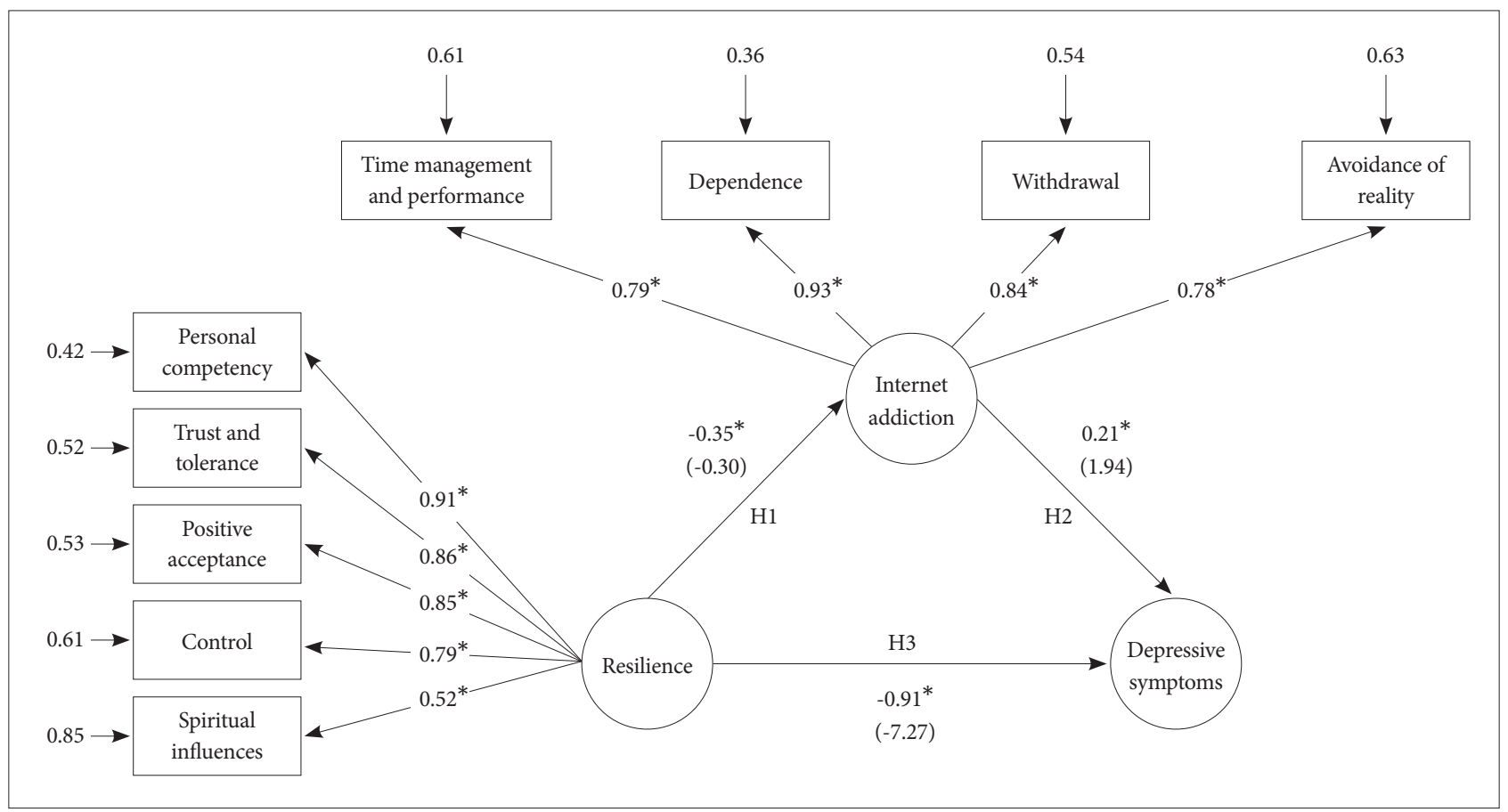

Figure 2. Measurement model (Model 1) for internet addiction, resilience, and depressive symptoms. Unstandardized parameter estimates are shown in parentheses under the standardized parameter estimates. ${ }^{*} p<0.05$. Resilience was measured by Connor-Davidson Resilience Scale (CD-RTSC). Internet Addiction was measured by Internet Addiction Test (IAT). Depressive symptoms was measured by Patient Health Questionnaire (PHQ-9).

Table 3. Fit indices for the tested measurement models

\begin{tabular}{lcccccccc}
\hline & $\chi^{2}$ & $\mathrm{df}$ & $\chi^{2} / \mathrm{df}$ & NFI & NNFI & CFI & RMSEA (90\%CI) & AIC \\
\hline Model 1 & 36.951 & 29 & 1.27 & 0.990 & 0.997 & 0.998 & $0.018(0.001-0.034)$ & -21.049 \\
Model 2 & 93.412 & 29 & 3.22 & 0.974 & 0.972 & 0.982 & $0.052(0.040-0.063)$ & 35.412 \\
Model 3 & 104.070 & 29 & 3.59 & 0.971 & 0.967 & 0.979 & $0.056(0.044-0.067)$ & 46.070 \\
Model 4 & 113.791 & 29 & 3.92 & 0.968 & 0.968 & 0.976 & $0.058(0.047-0.069)$ & 52.791 \\
\hline
\end{tabular}

NFI: normed fit index, NFI: non-normed fit index, CFI: comparative fit index, RMSEA: root mean square error of approximation, CI: confidence interval, AIC: Akaike Information Criterion

$\mathrm{p}<0.001)$. The fit indices for Model 3 were as follow: NFI of 0.971, NNFI of 0.967 , CFI of 0.979, RMSEA of 0.056 (90\%CI $=0.0044-0.067$ ), and AIC of 46.070 (Table 3 and 4). In model 4, internet addiction had a significant and positive total effect on depressive symptoms $(\beta=0.485, \mathrm{SE}=0.120$, $\mathrm{p}<0.001)$; and a significant and negative indirect effect on internet addiction through resilience $(\beta=-0.442, \mathrm{SE}=0.150$, $\mathrm{p}<0.001)$. The fit indices for Model 4 were as follow: NFI of 0.968 , NNFI of 0.968 , CFI of 0.976 , RMSEA of 0.058 (90\%CI=0.047-0.069), and AIC 52.791 (Table 3 and 4). Among Models 1 to 4, Model 1 was regarded as the most parsimonious model with satisfactory model fit (Table 3).

\section{DISCUSSION}

This study reported the mediating role of internet addiction between psychological resilience and depressive symp- toms among Korean university students, using a structural equation modeling approach. In our descriptive results, the higher level of resilience in university men than women is consistent to the previous findings from a twin study. ${ }^{56}$ Moreover, university women were found to have more depressive symptoms than men in this study. Such a sex difference was also reported previously in university students from Korea and US, ${ }^{57}$ as well as Europe. ${ }^{58}$ The average age of university men was higher than that of women in this sample, owing to the mandatory military services for Korean men. This may also contribute to the observed sex differences of the scores of major measures.

From the structural equation models, students with a lower level of resilience are generally more vulnerable to addictive internet behaviors which is consistent to the previous findings. ${ }^{59}$ Indeed, a poor defense or maladaptation system could be associated with Internet addiction. ${ }^{60} \mathrm{~A}$ meta-analy- 
Table 4. Decompositions of effects in the tested structural equation models

\begin{tabular}{lcc}
\hline & B (SE) & p \\
\hline Model 1 & & \\
Total effect & $-0.981(0.514)$ & $<0.001$ \\
Resilience $\rightarrow$ Depressive symptoms & & \\
Indirect effec & $-0.073(0.183)$ & $<0.001$ \\
Resilience $\rightarrow$ Internet addiction & & \\
$\rightarrow$ Depressive symptoms & & \\
Model 2 & & \\
Total effect & $-0.350(0.065)$ & $<0.001$ \\
Resilience $\rightarrow$ Internet addiction & & \\
Indirect effect & $-0.337(0.110)$ & $<0.001$ \\
Resilience $\rightarrow$ Depressive symptoms & & \\
$\rightarrow$ Internet addiction & & \\
Model 3 & & \\
Total effect & & \\
Internet addiction & & \\
$\rightarrow$ Depressive symptoms & & \\
Indirect effect & & \\
Internet addiction $\rightarrow$ Resilience & & \\
$\rightarrow$ Depressive symptoms & & \\
Model 4 & & \\
Total effect & & \\
Depressive symptoms & & \\
Indirect effect & & \\
Depressive symptoms $\rightarrow$ Resilience & & \\
$\rightarrow$ Internet addiction & & \\
\hline
\end{tabular}

Resilience was measured by Connor-Davidson Resilience Scale (CD-RISC), Internet Addiction was measured by Internet Addiction Test (IAT), Depressive symptoms was measured by Patient Health Questionnaire (PHQ-9)

sis of internet addiction studies in Korea also revealed that poor coping of stress is a risk factor of internet addiction. ${ }^{61} \mathrm{In}$ reverse, better coping style ${ }^{62}$ and adaptations ${ }^{60}$ are protective against the risks of addictive internet behaviors. The association between internet addiction and more depressive symptoms could be viewed as one of the psychiatric comobidities of internet addiction, as shown in a meta-analysis. ${ }^{63}$ At the same time, the association of higher resilience with less depressive symptoms observed is probably due to more effective coping strategies against adverse conditions for the resilient group than others. ${ }^{64,65} \mathrm{~A}$ further examination of the domains of the scales being used to assess psychological resilience and internet addiction could help explain the association between psychological resilience and risks of internet addiction. One of the characteristics of addictive internet behaviors is poor time management. Resilient students with better personal competency (awareness and self-management) and stress tolerance could avoid entering into an adap- tive state of developing internet dependence and later withdrawal. Finally, resilient students could better trust in own instinct, to maintain healthy spirituality and control themselves from avoiding reality. When applying these results to real life, students with stronger resilience would be less susceptible to the comobidity of internet addiction than their peers, and have a better transition from adolescents to young adults.

There are some limitations to the interpretation of results and applications to health promotion and clinical practices. With a cross-sectional study design, the casual relationships between the major variables could not be established. The major variables used to construct the measurement models were based on self-reported information. Social desirability and recall biases recall biases could affect the internal validity. According to Soule et al., ${ }^{66}$ there are six major forms of internet addiction, including communication addiction and game addiction. The mediation effect of internet addiction on the association between psychological resilience and depressive symptoms found in this study may not be generalized to all forms of internet addiction. Unlike PHQ-15, PHQ-9 does not screen for somatic symptoms, which could be related to depression. ${ }^{67}$ However, three typical depressive symptoms, namely depressed mood, anhedonia, and reduced energy from DSM-IV-TR and ICD-10 are covered by PHQ-9. PHQ9 has also been used to screen depressive symptoms related to maladaptive use of information technology, such as Facebook. ${ }^{68}$ Personality which is one of the key determinants of internet behaviors; ${ }^{69}$ as well as other potential mediators including social support, ${ }^{70}$ coping styles, ${ }^{71}$ and coping flexibility ${ }^{72}$ were not investigated in this study. In addition, sleep quality which could mediate internet addiction and depression in university students ${ }^{73}$ was not included.

According to the Korean Education Statistics Service, there are 183483 male (51.6\%) and 172289 (48.4\%) female students enrolled in universities in Korea. When comparing this ratio with that of our sample, only a small Cohen effect size of 0.12 was found. This suggests a representative sample being used in this study. To ensure the parsimoniousness of the resulting model, possible mediation models with depression ${ }^{74}$ and resilience as mediators ${ }^{38}$ were enumerated and tested before the final model was confirmed. Furthermore, all candidate models were tested with stratification by sex, as a sensitivity test. Although available literature stated that using gaming as maladaptive coping strategies are relatively more common in men than women, ${ }^{75}$ our final model was applicable to both university men and women.

The current results have important implications for future development of guidelines of resilience-based interventions of negative affects. ${ }^{76}$ Exercise-based intervention was found to be effective in reducing psychological symptoms relating 
to internet addiction, including depression (standardized mean difference $=-0.85,95 \% \mathrm{CI}=-1.20$ to -0.49 ) in a metaanalysis among East Asian studies. Exercise-based resilience strengthening programs could potentially be incorporated into clinical practices for reducing depressive symptoms. ${ }^{77}$

In conclusion, internet addiction mediates the associations between resilience and depressive symptoms in Korean university students. Enhancing resilience is important to prevent addictive internet behaviors and the related depressive symptoms among young people.

\section{REFERENCES}

1. Ayuso-Mateos JL, Nuevo R, Verdes E, Naidoo N, Chatterji S. From depressive symptoms to depressive disorders: the relevance of thresholds. Br J Psychiatry 2010;196:365-371.

2. Hopkins K, Crosland P, Elliott N, Bewley S; Clinical Guidelines Update Committee B. Diagnosis and management of depression in children and young people: summary of updated NICE guidance. BMJ 2015;350:h824.

3. Thapar A, Collishaw S, Pine DS, Thapar AK. Depression in adolescence. Lancet 2012;379:1056-1067.

4. Southwick SM, Bonanno GA, Masten AS, Panter-Brick C, Yehuda R. Resilience definitions, theory, and challenges: interdisciplinary perspectives. Eur J Psychotraumatol 2014;5.

5. Reinherz HZ, Paradis AD, Giaconia RM, Stashwick CK, Fitzmaurice G. Childhood and adolescent predictors of major depression in the transition to adulthood. Am J Psychiatry 2003;160:2141-2147.

6. Masten AS, Burt KB, Roisman GI, ObradoviĆ J, Long JD, Tellegen A. Resources and resilience in the transition to adulthood: continuity and change. Dev Psychopathol 2004;16:1071-1094.

7. Elisei S, Sciarma T, Verdolini N, Anastasi S. Resilience and depressive disorders. Psychiatr Danub 2013;25(Suppl 2):S263-S267.

8. Russo SJ, Murrough JW, Han MH, Charney DS, Nestler EJ. Neurobiology of Resilience. Nat Neurosci 2012;15:1475-1484.

9. Strohmaier J, Amelang M, Hothorn LA, Witt SH, Nieratschker V, Gerhard D, et al. The psychiatric vulnerability gene CACNA1C and its sex-specific relationship with personality traits, resilience factors and depressive symptoms in the general population. Mol Psychiatry 2013;18:607-613.

10. Burt KB, Whelan R, Conrod PJ, Banaschewski T, Barker GJ, Bokde ALW, et al. Structural brain correlates of adolescent resilience. J Child Psychol Psychiatry 2016;57:1287-1296.

11. Galinowski A, Miranda R, Lemaitre H, Paillère Martinot ML, Artiges $\mathrm{E}$, Vulser H, et al. Resilience and corpus callosum microstructure in adolescence. Psychol Med 2015;45:2285-2294.

12. Chan SW, Harmer CJ, Norbury R, O'Sullivan U, Goodwin GM, Portella MJ. Hippocampal volume in vulnerability and resilience to depression. J Affect Disord 2016;189:199-202.

13. Rew L, Horner SD. Youth resilience framework for reducing healthrisk behaviors in adolescents. Pediatr Nurs 2003;18:379-388.

14. Hodder RK, Freund M, Bowman J, Wolfenden L, Campbell E, Wye P, et al. A cluster randomised trial of a school-based resilience intervention to decrease tobacco, alcohol and illicit drug use in secondary school students: study protocol. BMC Public Health 2012;12:1009.

15. Hodder RK, Daly J, Freund M, Bowman J, Hazell T, Wiggers J. A schoolbased resilience intervention to decrease tobacco, alcohol and marijuana use in high school students. BMC Public Health 2011;11:722.

16. Colgan Y, Turnbull DA, Mikocka-Walus AA, Delfabbro P. Determinants of resilience to cigarette smoking among young Australians at risk: an exploratory study. Tob Induc Dis 2010;8:7.

17. Davis SJ, Spillman S. Reasons for drug abstention: a study of drug use and resilience. J Psychoactive Drugs 2011;43:14-19.
18. Zhou Z, Zhu H, Li C, Wang J. Internet addictive individuals share impulsivity and executive dysfunction with alcohol-dependent patients. Front Behav Neurosci 2014;8:288.

19. Mitchell MR, Potenza MN. Addictions and personality traits: impulsivity and related constructs. Curr Behav Neurosci Rep 2014;1:1-12.

20. Carli V, Durkee T, Wasserman D, Hadlaczky G, Despalins R, Kramarz E, et al. The association between pathological internet use and comorbid psychopathology: a systematic review. Psychopathology 2013;46:1-13.

21. Zhou P, Zhang C, Liu J, Wang Z. The relationship between resilience and internet addiction: a multiple mediation model through peer relationship and depression. Cyberpsychol Behav Soc Netw 2017; 20: 634-639.

22. Li X, Shi M, Wang Z, Shi K, Yang R, Yang C. Resilience as a predictor of internet addiction: The mediation effects of perceived class climate and alienation. 2010 IEEE 2nd Symposium on Web Society, 2010 Aug 16-17; Beijing, China. IEEE; 2010. p.66-70.

23. Terwase JM, Ibaishwa RL. Resilience, shyness and loneliness as predictors of internet addiction among university undergraduate students in benue state country. J Hum Soc Sci 2014;19:1-7.

24. Chakraborti A, Ray P, Islam M, Mallick A. Medical undergraduates and pathological internet use: Interplay of stressful life events and resilience. J Health Spec 2016;4:56-63.

25. Choi SW, Kim DJ, Choi JS, Ahn H, Choi EJ, Song WY, et al. Comparison of risk and protective factors associated with smartphone addiction and Internet addiction. J Behav Addict 2015;4:308-314.

26. Kim SM, Huh HJ, Cho H, Kwon M, Choi JH, Ahn HJ, et al. The effect of depression, impulsivity, and resilience on smartphone addiction in university students. J Korean Neuropsychiatr Assoc 2014;53:214-220.

27. Dalbudak E, Evren C, Aldemir S, Evren B. The severity of Internet addiction risk and its relationship with the severity of borderline personality features, childhood traumas, dissociative experiences, depression and anxiety symptoms among Turkish university students. Psychiatry Res 2014;219:577-582.

28. Yen JY, Yen CF, Wu HY, Huang CJ, Ko CH. Hostility in the real world and online: the effect of internet addiction, depression, and online activity. Cyberpsychol Behav Soc Netw 2011;14:649-655.

29. Alpaslan AH, Soylu N, Kocak U, Guzel HI. Problematic internet use was more common in Turkish adolescents with major depressive disorders than controls. Acta Paediatr 2016;105:695-700.

30. Hirao K. Difference in mental state between Internet-addicted and non-addicted Japanese undergraduates. Int J Adolesc Med Health 2015;27:307-310.

31. Ni X, Yan H, Chen S, Liu Z. Factors influencing internet addiction in a sample of freshmen university students in China. Cyberpsychol Behav 2009;12:327-330.

32. Gamez-Guadix M. Depressive symptoms and problematic internet use among adolescents: analysis of the longitudinal relationships from the cognitive-behavioral model. Cyberpsychol Behav Soc Netw 2014;17: 714-719.

33. Lai CM, Mak KK, Watanabe H, Jeong J, Kim D, Bahar N, et al. The mediating role of Internet addiction in depression, social anxiety, and psychosocial well-being among adolescents in six Asian countries: a structural equation modelling approach. Public Health 2015;129:1224-1236.

34. Geisel O, Panneck P, Stickel A, Schneider M, Muller CA. Characteristics of social network gamers: results of an online survey. Front Psychiatry 2015;6:69.

35. Beck AT, Bredemeier K. A Unified model of depression: integrating clinical, cognitive, biological, and evolutionary perspectives. Clin Psychol Sci 2016;4:596-619.

36. Roy A, Sarchiapone M, Carli V. Low resilience in suicide attempters: relationship to depressive symptoms. Depress Anxiety 2007;24:273-274.

37. Lee H, Williams RA. Effects of parental alcoholism, sense of belonging, and resilience on depressive symptoms: a path model. Subst Use Misuse 2013;48:265-273.

38. Wisniewski P, Jia H, Wang N, Zheng S, Xu H, Rosson MB, et al. Resilience mitigates the negative effects of adolescent internet addiction 
and online risk exposure. Proceedings of the 33rd Annual ACM Conference on Human Factors in Computing Systems; 2015 April 18-23; Seoul, Republic of Korea. New York: ACM, 2015. p.4029-4038.

39. Yang L, Sun L, Zhang Z, Sun Y, Wu H, Ye D. Internet addiction, adolescent depression, and the mediating role of life events: finding from a sample of Chinese adolescents. Int J Psychol 2014;49:342-347.

40. Jang JN, Choi YH. Pathways from family strengths and resilience to internet addiction in male high school students: mediating effect of stress. J Korean Public Health Nurs 2012;26:375-388.

41. Lee K, Lee HK, Kim SH. Temperament and character profile of college students who have suicidal ideas or have attempted suicide. J Affect Disord 2017;221:198-204.

42. Choi SB, Lee W, Yoon JH, Won JU, Kim DW. Risk factors of suicide attempt among people with suicidal ideation in South Korea: a crosssectional study. BMC Public Health 2017;17:579.

43. Connor KM, Davidson JR. Development of a new resilience scale: the Connor-Davidson Resilience Scale (CD-RISC). Depress Anxiety 2003; 18:76-82.

44. Campbell-Sills L, Stein MB. Psychometric analysis and refinement of the Connor-davidson Resilience Scale (CD-RISC): Validation of a 10item measure of resilience. J Trauma Stress 2007;20:1019-1028.

45. Fernandez-Villa T, Molina AJ, Garcia-Martin M, Llorca J, DelgadoRodriguez M, Martin V. Validation and psychometric analysis of the Internet Addiction Test in Spanish among college students. BMC Public Health 2015;15:953.

46. Jelenchick LA, Becker T, Moreno MA. Assessing the psychometric properties of the Internet Addiction Test (IAT) in US college students. Psychiatry Res 2012;196:296-301.

47. Ko CH, Hsiao S, Liu GC, Yen JY, Yang MJ, Yen CF. The characteristics of decision making, potential to take risks, and personality of college students with Internet addiction. Psychiatry Res 2010;175:121-125.

48. Lee K, Lee HK, Gyeong H, Yu B, Song YM, Kim D. Reliability and validity of the Korean version of the internet addiction test among college students. J Korean Med Sci 2013;28:763-768.

49. Williams A, Larocca R, Chang T, Trinh NH, Fava M, Kvedar J, et al. Web-based depression screening and psychiatric consultation for college students: a feasibility and acceptability study. Int J Telemed Appl 2014;2014:580786.

50. Zhang YL, Liang W, Chen ZM, Zhang HM, Zhang JH, Weng XQ et al. Validity and reliability of Patient Health Questionnaire-9 and Patient Health Questionnaire-2 to screen for depression among college students in China. Asia Pac Psychiatry 2013;5:268-275.

51. Yoon S, Lee Y, Han C, Pae CU, Yoon HK, Patkar AA, et al. Usefulness of the Patient Health Questionnaire-9 for Korean medical students. Acad Psychiatry 2014;38:661-667.

52. Bentler PM, Bonett DG. Significance tests and goodness of fit in the analysis of covariance-structures. Psychol Bull 1980;88:588-606.

53. Bentler PM. Comparative fit indexes in structural models. Psychol Bull 1990;107:238-246.

54. Steiger JH. Structural model evaluation and modification: an interval estimation approach. Multivariate Behav Res 1990;25:173-180.

55. Bentler PM. On the fit of models to covariances and methodology to the bulletin. Psychol Bull 1992;112:400-404.

56. Amstadter AB, Myers JM, Kendler KS. Psychiatric resilience: longitudinal twin study. Br J Psychiatry 2014;205:275-280.

57. Kwon H, Yoon KL, Joormann J, Kwon JH. Cultural and gender differences in emotion regulation: relation to depression. Cogn Emot 2013; 27:769-782.

58. Ristic-Ignjatovic D, Hinic D, Jakovljevic M, Fountoulakis K, Siepera M, Rancic N. A ten-year study of depressive symptoms in Serbian medical students. Acta Clin Croat 2013;52:157-163.
59. Al-Gamal E, Alzayyat A, Ahmad MM. Prevalence of internet addiction and its association with psychological distress and coping strategies among university students in Jordan. Perspect Psychiatr Care 2016;52:49-61.

60. Yao B, Han W, Zeng L, Guo X. Freshman year mental health symptoms and level of adaptation as predictors of Internet addiction: a retrospective nested case-control study of male Chinese college students. Psychiatry Res 2013;210:541-547.

61. Koo HJ, Kwon JH. Risk and protective factors of internet addiction: a meta-analysis of empirical studies in Korea. Yonsei Med J 2014;55: 1691-1711.

62. Tang J, Yu Y, Du Y, Ma Y, Zhang D, Wang J. Prevalence of internet addiction and its association with stressful life events and psychological symptoms among adolescent internet users. Addict Behav 2014;39:744-747.

63. Ho RC, Zhang MW, Tsang TY, Toh AH, Pan F, Lu Y, et al. The association between internet addiction and psychiatric co-morbidity: a metaanalysis. BMC Psychiatry 2014;14:183.

64. Steinhardt M, Dolbier C. Evaluation of a resilience intervention to enhance coping strategies and protective factors and decrease symptomatology. J Am Coll Health 2008;56:445-453.

65. Nazir A, Mohsin H. Coping styles, aggression and interpersonal conflicts among depressed and non-depressed people. Health Promot Perspect 2013;3:80-89.

66. Soule LC, Shell LW, Kleen BA. Exploring internet addiction: demographic characteristics and stereotypes of heavy internet users. J Comput Inform Syst 2003;44:64-73.

67. Han H, Wang SM, Han C, Lee SJ, Pae CU. The relationship between somatic symptoms and depression. Neuro Endocrinol Lett 2014;35:463-469.

68. Tran TB, Uebelacker L, Wenze SJ, Collins C, Broughton MK. Adaptive and maladaptive means of using facebook: a qualitative pilot study to inform suggestions for development of a future intervention for depression. J Psychiatr Pract 2015;21:458-473.

69. Cho SC, Kim JW, Kim BN, Lee JH, Kim EH. Biogenetic temperament and character profiles and attention deficit hyperactivity disorder symptoms in Korean adolescents with problematic Internet use. Cyberpsychol Behav 2008;11:735-757.

70. Reinelt E, Barnow S, Stopsack M, Aldinger M, Schmidt CO, John U, et al. Social support and the serotonin transporter genotype (5-HTTLPR) moderate levels of resilience, sense of coherence, and depression. Am J Med Genet B Neuropsychiatr Genet 2015;168B:383-391.

71. Mahmoud JS, Staten R, Hall LA, Lennie TA. The relationship among young adult college students' depression, anxiety, stress, demographics, life satisfaction, and coping styles. Issues Ment Health Nurs 2012; 33:149-156.

72. Kato T. Development of the coping flexibility scale: evidence for the coping flexibility hypothesis. J Couns Psychol 2012;59:262-273.

73. Bhandari PM, Neupane D, Rijal S, Thapa K, Mishra SR, Poudyal AK. Sleep quality, internet addiction and depressive symptoms among undergraduate students in Nepal. BMC Psychiatry 2017;17:106.

74. Cho S, Kwon JH. The effect of emotion regulation on internet game overuse: a mixture of buffering effect and promoting effect. Kor J Clin Psychol 2015;34:411-428.

75. Chen KH, Oliffe JL, Kelly MT. Internet gaming disorder: an emergent health issue for men. Am J Mens Health 2018;12:1151-1159.

76. Luthar SS, Cicchetti D. The construct of resilience: implications for interventions and social policies. Dev Psychopathol 2000;12:857-885.

77. Yoshikawa E, Nishi D, Matsuoka YJ. Association between regular physical exercise and depressive symptoms mediated through social support and resilience in Japanese company workers: a cross-sectional study. BMC Public Health 2016;16:553. 